\title{
Prevalence of Self-reported Urinary Incontinence in Community-dwelling Older Adults of Westmoreland, Jamaica
}

\author{
Otaniyenuwa Asemota MD, Denise Eldemire-Shearer MBBS PhD, Norman K. Waldron MBBS MPH, \\ Aileen Standard-Goldson MD
}

\begin{abstract}
INTRODUCTION Urinary incontinence is a disorder of considerable significance in older adults. It causes distress and morbidity, yet its true prevalence in the community is likely underestimated, because stigma and other factors may cause underreporting. WHO has developed a 10-minute screening tool to help primary healthcare providers recognize and manage the most common geriatric conditions: falls, memory loss, depression and urinary incontinence.

OBJECTIVE Determine prevalence of urinary incontinence in adults aged $\geq 60$ years in Westmoreland Parish, Jamaica; examine some of the associated risk factors; estimate how much urinary incontinence goes unreported and explore related barriers.

METHODS A cross-sectional study in April 2014 of 454 older adults was conducted in 12 community clusters in Westmoreland. Data collection was done using an interviewer-administered questionnaire. Data were analyzed using SPSS version 17. Chi-square and Fisher exact tests were used to assess significance of associations between dependent and independent variables.
\end{abstract}

RESULTS The majority $(241 / 454,53.1 \%)$ of respondents were men aged 60-95 years (median age 69 years; interquartile range: 64-77).

\section{INTRODUCTION}

Urinary incontinence (UI), defined as any involuntary loss of urine,[1] is a recognized major geriatric condition associated with significant suffering, cost and reduced quality of life for affected individuals.[2-16] In WHO's Age-Friendly Primary Health Care Centres Toolkit produced in 2008, UI is listed as one of four geriatric "giants" (in terms of population impact).[4] It affects both men and women, with a higher prevalence among women.[3] The number of people with $\mathrm{UI}$ is expected to increase as the global population ages, because UI prevalence increases with advancing age. $[3,12,15]$ There are no solid estimates of current global prevalence, but a systematic review of just one subtype of UI found prevalence as high as 55\%.[17] Prevalence estimates vary greatly, because of factors such as differing case definitions, differences in population studied, and type of survey questions used.[2,6,10]

UI lends itself to considerable stigma and sensitivity across varied cultural contexts. As a result, it is widely acknowledged that actual UI prevalence in the community is higher than generally reported, because a substantial proportion of persons with $\mathrm{UI}$ fail to report it to health care providers. $[2,3,6-8,11]$ This has led to recommendations for systematic screening of older adults by health care providers, especially at the primary care level, to facilitate earlier detection of UI symptoms.[4,5,9,11]

UI may negatively impact a person's psychosocial well-being and can lead to social isolation and withdrawal.[16,18-20] In some cases where older adults live alone, it also creates difficulty with
Prevalence of urinary incontinence was $10.6 \%$ (48/453). Statistically significant associations were found between urinary incontinence and hypertension, diabetes mellitus, prostate problems and arthritis, but not with kidney problems, stroke or parity. Among respondents with urinary incontinence, $30.2 \%$ had not reported the condition to their doctor (13/43 who answered this question). Reasons cited for nonreporting included belief that urinary incontinence is normal with aging (9 respondents), not being bothered by urinary incontinence (7), inability to pay for treatment (6), feeling ashamed to report the condition (4), not knowing the appropriate doctor to see (2) and lack of awareness of available treatment options (1). Among respondents who had unreported urinary incontinence, 10 indicated a preference for physician-initiated (as opposed to self-initiated) discussion of urinary incontinence.

CONCLUSION The substantial prevalence of urinary incontinence and high rate of nonreporting (almost one in three) underscore the need for systematic screening of older adults by doctors, especially at the primary care level, for early detection and appropriate urinary incontinence management.

KEYWORDS Urinary incontinence, prevalence, risk factors, crosssectional studies, aged, elderly, Jamaica daily life and maintaining personal hygiene. It has been shown that $\mathrm{UI}$ is more prevalent in older adults with stroke, diabetes and those with limitations in basic activities of daily living such as walking across a room.[21] However, when they do not live alone, the condition may increase caregiver burden, and may be a major reason for institutionalization of some older adults.[11-16,18]

The objectives of this study were to determine $\mathrm{UI}$ prevalence (total and unreported) in adults aged $\geq 60$ years in Westmoreland, Jamaica, examine some of its associated risk factors, and estimate degree of nonreporting and determine barriers to reporting.

\section{METHODS}

This was a cross-sectional study in April 2014 of 454 noninstitutionalized older adults drawn from 12 community clusters in Westmoreland, one of 14 parishes (administrative divisions) in Jamaica. According to the most recent data from the Statistical Institute of Jamaica, Westmoreland had a total population of 144,817 in 2012, $16,659(11.5 \%)$ of whom were aged $\geq 60$ years.[22]

The following operational definitions were used:

- Older adults were defined as persons aged $\geq 60$ years at their last birthday. $[4,5]$

- UI was defined as wetting self with urine at least once in the past year.[1,4]

- Normal residence was defined as living in a community for at least 3 consecutive months out of the last 12 .

- Quantification of urine loss was done subjectively using patient's perception of leakage frequency and leakage vol- 
ume. Respondents who reported UI were asked to select frequency of leakage from once a year, several times a year, once a month, more than once a month, once a week, a few times a week, once a day and many times a day. For data analysis, leakage that occurred at least once a week was classified as frequent while less frequent leakage was classified as infrequent. Leakage volume perception was indicated by one of three options; a small amount, more than a small amount but not a lot, and a lot. The Incontinence Impact Questionnaire (ICIQ), an internationally validated UI questionnaire, used similar terms in categorizing leakage volume perception.[1]

- When UI was reported following effort such as sneezing, coughing, laughing, lifting or bending, such cases were classified as stress UI. When it occurred following a strong urge or on hearing running water, those cases were classified as urge UI. When UI episodes occurred without prior urge or effort, without warning, or when they occurred in the setting of straining to pass urine, these were classed as suspected bladder outflow obstruction or suspected neurogenic origin and placed in the overflow UI group.[1,16]

- Associated risk factors and comorbidities inquired about included self-reported diabetes, high blood pressure, prostate problems, kidney problems, stroke, arthritis and parity.

- A dichotomous question determined whether respondents had reported UI to a doctor; open- and closed-ended questions explored their reasons.

Sampling strategy and sample size The calculated minimum sample size for this study was 150 eligible persons, using a formula from the UN International Fund for Agricultural Development.[23] The calculation assumed an $11 \%$ UI prevalence,[16] a confidence interval of $95 \%$ and type I error of $5 \%$. The calculated figure was multiplied by a design effect factor of 3 , to allow for cluster sampling, bringing the estimated desired sample size to 450 . A total of 460 questionnaires were sent out (allowing for some damage to or improper completion of forms), of which 454 returned questionnaires were found valid and entered into the data extraction pool.

The sample was drawn proportionate to population size from 12 community clusters in Westmoreland, with random selection of communities within clusters. Taken together, the clusters constitute the whole of Westmoreland Parish. Individual, private households (nursing homes were excluded) were visited in sequence, starting from a selected central location in each cluster. Where more than one eligible person was identified in a household, all were interviewed. Persons were excluded if they resided in nursing homes; were paralyzed, bedridden or used urinary catheters; or if the caregiver reported severe mental disabilities. Exclusion was done in situ by interviewers, who ascertained eligibility from responsible adults in the household and conducted interviews only with eligible older adults.

Data collection An interviewer-administered questionnaire consisting of 42 items was designed for this study. Before developing the questionnaire, existing literature on UI was reviewed. The literature search was conducted in PubMed and SciELO databases using the keywords "urinary incontinence," "unreported" and "elderly". The ICIQ[1] and the Urogenital Distress Inventory were also evaluated for reference.[24] It was deemed preferable to develop a unique questionnaire, as existing tools did not cov- er the breadth of information sought by researchers, and, to the authors' knowledge, the ICIQ had not been previously validated in the Jamaican population.

The questionnaire was piloted in Hanover, an adjacent parish with rural-urban populations similar to Westmoreland's. Ten questionnaires were administered in the pilot phase and analyzed for face and content validity, to ensure that questions were sufficiently clear and comprehensive to capture the relevant data range. The complete questionnaire is available online at http://www.medicc .org/mediccreview/asemota.html.

Data analysis We analyzed data using SPSS 17 for Windows. chi-square and Fisher exact tests were used to assess statistical significance of associations between dependent (UI) and independent variables (with threshold $p=0.05$ ). Where missing data occurred and this was not deemed sufficient to invalidate the item in question, the total number of valid data units for that item was used in each analysis (denominator).

Ethics The study protocol was approved by the Faculty of Medical Sciences/University Hospital of the West Indies' Ethics Committee and by the Jamaican Ministry of Health's Advisory Panel on Ethics and Medico-Legal Affairs, before data collection began. Written informed consent was obtained from participants before interview. Identification numbers were assigned to participants to ensure anonymity.

\section{RESULTS}

The majority $(241 / 454 ; 53.1 \%)$ respondents were men. The age range was $60-95$ years, with median age 69 years (interquartile range: $64-77$ ).

Overall UI prevalence among those surveyed was $10.6 \%$ (48/453), $12.7 \%$ in women (27/213) and $8.8 \%$ in men (21/240). The difference was not statistically significant $(p=0.1)$. One questionnaire contained an ambiguous response to the question about incontinence in the past year and so was omitted from all related analyses. UI prevalence was significantly higher in older people: $7 \%(16 / 229)$ in the group aged $60-69$ years, $13 \%(18 / 138)$ in the group aged $70-79$ years, and $16 \%(14 / 86)$ in those aged $\geq 80$ years. The prevalence of urge, stress and overflow incontinence in respondents with UI was $87 \%$ (39/45), $32 \%(15 / 47)$, and $68 \%$ (32/47), respectively; the categories were not mutually exclusive. There were three improperly completed questionnaires for urge, one for stress and one for overflow incontinence. A higher proportion of persons with stress incontinence belonged to the group aged $60-69$ years $(40 \%$; 6/15), compared with the older age groups (Table 1).

Table 2 displays data on associations between UI and selected comorbidities and risk factors. Hypertension, diabetes mellitus, prostate problems and arthritis were found significantly more frequently in persons with UI. Kidney problems and prior stroke were more frequent among persons with UI, but the differences were not statistically significant, nor were there significant differences by parity.

Of 43 older adults with UI who answered the question "have you told your doctor about the urine leakage since the problem started?", 30 had reported it to their physician, 17 women and 
Table 1: Distribution of Ul type by age group $(n=48)$

\begin{tabular}{|c|c|c|c|c|}
\hline \multirow{3}{*}{ Ul type } & \multicolumn{4}{|c|}{ Distribution n (\%) } \\
\hline & \multicolumn{4}{|c|}{ Age group (years) } \\
\hline & $60-69$ & $70-79$ & $\geq 80$ & Total \\
\hline \multicolumn{5}{|l|}{ Urge } \\
\hline Yes & 14 (35.9) & $14(35.9)$ & $11(28.2)$ & $39(100)$ \\
\hline No & $1(16.7)$ & $2(33.3)$ & $3(50.0)$ & $6(100)$ \\
\hline Missing data & 1 & 2 & & 3 \\
\hline \multicolumn{5}{|l|}{ Stress } \\
\hline Yes & $6(40.0)$ & $5(33.3)$ & $4(26.7)$ & $15(100)$ \\
\hline No & $9(28.1)$ & $13(40.6)$ & $10(31.3)$ & $32(100)$ \\
\hline Missing data & 1 & & & 1 \\
\hline \multicolumn{5}{|l|}{ Overflow } \\
\hline Yes & $9(28.1)$ & $12(37.5)$ & $11(34.4)$ & $32(100)$ \\
\hline No & $7(46.7)$ & $5(33.3)$ & $3(20.0)$ & $15(100)$ \\
\hline Missing data & & 1 & & 1 \\
\hline
\end{tabular}

UI: urinary incontinence

Table 2: Risk factors and comorbidities in older adults with and without urinary incontinence

\begin{tabular}{|c|c|c|c|c|}
\hline \multirow{2}{*}{ Variable } & \multicolumn{3}{|c|}{ Urinary incontinence $\mathbf{n}(\%)^{*}$} & \multirow[b]{2}{*}{ p Value } \\
\hline & Yes & No & Total n (\%) & \\
\hline \multicolumn{5}{|c|}{ Age group (years) } \\
\hline $60-69$ & $16(33.3)$ & $213(52.6)$ & $229(50.6)$ & \multirow{4}{*}{$0.031^{\mathrm{a}}$} \\
\hline $70-79$ & $18(37.5)$ & $120(29.6)$ & $138(30.5)$ & \\
\hline $80+$ & $14(29.2)$ & $72(17.8)$ & $86(19.0)$ & \\
\hline Missing data & & 1 & 1 & \\
\hline \multicolumn{5}{|l|}{ Hypertension } \\
\hline Yes & $31(64.6)$ & $199(49.1)$ & $230(50.8)$ & $0.03^{a}$ \\
\hline No & $17(35.4)$ & $206(50.9)$ & $223(49.2)$ & \\
\hline Missing data & & 1 & 1 & \\
\hline \multicolumn{5}{|c|}{ Diabetes mellitus } \\
\hline Yes & $22(48.9)$ & 78 (19.9) & $100(22.9)$ & $<0.001^{a}$ \\
\hline No & $23(51.1)$ & $314(80.1)$ & $337(77.1)$ & \\
\hline Missing data & 3 & 14 & 17 & \\
\hline \multicolumn{5}{|c|}{ Prostate problems } \\
\hline Yes & $5(26.3)$ & $18(8.3)$ & $23(9.8)$ & $0.026^{b}$ \\
\hline No & $14(73.7)$ & $198(91.7)$ & $212(90.2)$ & \\
\hline Missing data & 2 & 4 & 6 & \\
\hline \multicolumn{5}{|c|}{ Kidney problems } \\
\hline Yes & $2(4.4)$ & $3(0.8)$ & $5(1.1)$ & $0.083^{b}$ \\
\hline No & $43(95.6)$ & $394(99.2)$ & 437 (98.9) & \\
\hline Missing data & 3 & 9 & 12 & \\
\hline \multicolumn{5}{|l|}{ Stroke } \\
\hline Yes & $4(8.7)$ & $13(3.3)$ & $17(3.8)$ & $0.088^{b}$ \\
\hline No & 42 (91.3) & $385(96.7)$ & 427 (96.2) & \\
\hline Missing data & 2 & 8 & 10 & \\
\hline \multicolumn{5}{|l|}{ Arthritis } \\
\hline Yes & $31(67.4)$ & $151(37.8)$ & $182(40.8)$ & $<0.001^{a}$ \\
\hline No & $15(32.6)$ & $249(62.3)$ & $264(59.2)$ & \\
\hline Missing data & 2 & 6 & 8 & \\
\hline \multicolumn{5}{|l|}{ Parity } \\
\hline $0-1$ & $6(22.2)$ & $34(18.7)$ & 40 (19.1) & $0.80^{\mathrm{a}}$ \\
\hline $2-4$ & 7 (25.9) & $58(31.9)$ & 65 (31.1) & \\
\hline$\geq 5$ & $14(51.9)$ & $90(49.5)$ & $104(49.8)$ & \\
\hline Missing data & & 4 & 4 & \\
\hline
\end{tabular}

13 men. Of the 13 who had not reported it to their physicians, 4 reported" a small" amount of urine loss on each occasion, another 4 reported "more than a small amount but not a lot," and 5 reported "a lot" of urine loss. In the group that had reported UI to their physicians, 26/29 (1 invalid questionnaire) had urine loss at least once weekly compared to $10 / 13$ in the nonreporting group. Infrequent urine loss (less than once a week) occurred in 3/29 of those who had reported UI to their physicians and in $3 / 13$ of those who had not.

When respondents who had not reported UI to their physicians were asked why, nine cited the belief that $\mathrm{UI}$ is normal with aging; seven said UI did not bother them; six said they could not afford treatment; four cited shame about discussing UI with a doctor; two said they did not know an appropriate doctor to tell; and one believed there was no treatment available.

Persons with unreported UI were asked about their preference for physician/patient discussion of the condition. The majority (10/13) indicated a preference for physician-initiated discussion of UI. Two persons thought that either they or their physician should initiate the conversation and only one indicated that the physician should not initiate a discussion of UI.

The majority (24/30) of respondents who reported UI to a doctor received treatment, consisting of advice, medication, surgery or a combination of these. The most frequent treatment was medication (19). In the treatment group, 10 reported that treatment received had not helped and 14 that treatment had helped or somewhat helped.

\section{DISCUSSION}

The overall UI prevalence found in this survey was consistent with international reports, albeit somewhat lower. Tamanini reported a UI prevalence of $11.8 \%$ in Brazilian men and $26.2 \%$ in women aged $\geq 60$ years.[21] Goepel cited a prevalence of $11 \%$ for adults aged $\geq 60$ years in Germany.[16] We used a one-year UI prevalence; other definitions of prevalence may yield different outcomes.[2]

The statistically significant associations found in this study between $\mathrm{UI}$ and self-reported hypertension, diabetes mellitus, prostate problems and arthritis are comparable to previous reports. Tamanini reported that UI prevalence was higher in the presence of stroke, diabetes and functional limitations.[21] Markland concluded that high UI prevalence in women may be partially explained by diabetes prevalence, but could not conclude whether diabetes and prostate diseases were important factors accounting for increased UI prevalence in men.[10] Gerst reported that men with prostate problems were more than twice as likely to report urge UI, while odds of UI overall only slightly increased when functional limitations were present or as age increased (OR $=1.16 ; 95 \% \mathrm{Cl} 1.06-1.26$ and $1.05 ; 95 \% \mathrm{Cl} 1.01-1.09$ respectively).[19]

While the difference in frequency of self-reported stroke between respondents with and without UI was not statistically significant in our sample, the literature lists stroke and arthritis as risk factors for UI.[25,26] It is possible that arthritis and stroke, because of their negative effects on general mobility, may be linked with a higher UI prevalence. Tamanini reported that UI prevalence varied directly with the degree of dependence of the elderly person. 
[21] However, stroke may also be linked with UI via another mechanism besides mobility limitation. The Fourth International Consultation on Incontinence lists suprapontine cerebral lesions, including stroke, as possible causes of neurogenic UI.[1] Detrusor dysfunction due to impaired central control may be a mechanism in such cases.[1,26]

The use of medication, particularly antihypertensives, is an established risk factor for UI, as reported by Berlezi.[7] While our study found a statistically significant association between hypertension and UI, we did not investigate use of antihypertensives or differences between types of antihypertensives used. The literature notes that diuretics, calcium channel blockers, ACE inhibitors and beta blockers are the common antihypertensive drugs that may increase the risk of developing UI. $[7,26]$

We found a somewhat lower prevalence of unreported UI than seen in the existing literature. Visser reported $64 \%$ in women aged $\geq 55$ years in general practices in the Netherlands.[9] Only $51 \%$ of Berger's study participants had sought health care for UI, and Wallner found $53 \%$ undiagnosed UI.[15,27] All three studies exclusively surveyed women and included adults aged $<60$ years. $[9,15,27]$ It is possible that younger age and female sex influenced reluctance to discuss UI symptoms with care providers. Younger women may be less likely to divulge potentially embarrassing personal information. However, our results suggest that in the group aged $\geq 60$ years, women are more likely than their male counterparts to report UI symptoms.

Other reasons we found for nonreporting are similar to those reported in previous studies. Teunissen also found that many older adults believe UI to be a normal part of aging and gave this as a reason for not having sought help.[6] This represents an opportunity for greater public education by healthcare providers and policymakers, focused on educating older adults about what constitutes normal aging and what is pathological.

Embarrassment and feelings of shame may play a role in nonreporting of $\mathrm{UI}$ but only a minority of our respondents gave this motive, consistent with Teunissen's findings.[6] .

The fact that almost half our respondents who failed to report UI to their provider cited inability to pay for UI treatment raises social concerns. Inability to afford UI care may also reflect an inability to afford care for other age-related chronic diseases. The impact of poverty on the health and well-being of older adults—and indeed on the poor in general-is a major social challenge that must be addressed by policymakers.

More than two thirds of older adults with unreported UI stated that they would prefer to be asked about urinary symptoms by their doctors. This underscores the need for doctors, especially in primary care, to screen systematically for UI symptoms in older adults. We recommend an initial thorough assessment of older adults with UI before prescribing any form of treatment. This should include a thorough history of symptoms, including duration, severity and also a measure of their perceived impact on quality of life. Initial treatment with medications without proper ascertainment of cause and type of UI may lead to early treatment failure, causing further patient discouragement and likely resulting in loss to followup.

Strengths and limitations This was the first community-based study to examine in detail self-reported $\mathrm{UI}$ among older adults in Jamaica. Self reports are susceptible to exaggeration or understatement, depending on the question asked and the social desirability of the response given. A respondent's perception of the condition's impact on their health may also influence the response. Since this study depended on self report to assess both UI and its risk factors and comorbid conditions, in the absence of objective validation protocols, under- or overreporting may have occurred. There are precedents for quantifying urine loss volume subjectively. The ICIQ also quantified urine as "small amount", "moderate amount" and "large amount."[1] Equally subjective descriptions have been used, such as "droplets," "dashes" and "whole bladder."[3] Recall bias may affect responses in a cross-sectional study such as this. Potential cultural stigma associated with UI may lead to information bias and the presence of an interviewer may have negatively impacted on respondents' willingness to admit to urine leakage. Finally, exclusion of institutionalized older adults may have resulted in an underestimation of overall UI prevalence.

\section{CONCLUSIONS}

$\mathrm{UI}$ is prevalent among older adults in Westmoreland Parish, Jamaica, remaining unreported (and therefore undiagnosed and untreated) in many of those affected. The incorrect belief that UI is a normal part of aging contributes to suboptimal reporting, so attention should be directed at increasing the health literacy of our population so that older adults can distinguish between what constitutes normal aging and what is pathological. Family physicians should be encouraged to screen systematically for $\mathrm{UI}$ in older adults, using one of the simple and effective screening tools available to detect UI symptoms and other conditions frequent in the geriatric population. -1 .

\section{REFERENCES}

1. Abrams P, Andersson KE, Birder L, Brubaker L, Cardozo L, Chapple C, et al. Fourth International Consultation on Incontinence Recommendations of the International Scientific Committee: Evaluation and treatment of urinary incontinence, pelvic organ prolapse, and fecal incontinence. Neurourol Urodyn. 2010;29(1):213-40.

2. Ko Y, Lin SJ, Salmon JW, Bron MS. The impact of urinary incontinence on quality of life of the elderly. Am J Manag Care. 2005 Jul;11(4 Suppl):S103-11.

3. Knorst MR, Resende TL, Goldim JR. Clinical profile, quality of life and depressive symptoms of women with urinary incontinence attending a university hospital. Rev Bras Fisioter. 2011 MarApr;15(2):109-16. Portuguese, English.
4. World Health Organization. Age-Friendly Primary Health Care Centres Toolkit [Internet]. Geneva: World Health Organization; 2008 [cited 2015 Apr 7]. 114 p. Available from: http://apps.who.int/iris/ bitstream/10665/43860/1/9789241596480_eng .pdf?ua $=1$

5. Eldemire-Shearer D. Age Friendly Primary Health Care Clinical Toolkit. Mona Ageing \& Wellness Centre [Internet]. Mona (US): University of the West Indies. 2011 Jan [cited 2015 Apr 7]. 62 p. Available from: http://www.mona.uwi.edu/comm health/sites/default/files/commhealth/uploads/ complete-tool-kit.pdf

6. Teunissen D, van Weel C, Lagro-Janssen T. Urinary incontinence in older people living in the community: examining help- seeking behaviour. $\mathrm{Br} J$ Gen Pract. 2005 Oct;55(519):776-82.

7. Berlezi EM, Fiorin AAM, Bilibio PVF, Kirchner $\mathrm{RM}$, Oliveira KR. [Study of urinary incontinence in menopausal women users and nonusers of antihypertensive medication]. Rev Bras Geriatr Gerontol. 2011;14(3). Portuguese.

8. Silva L, Lopes $\mathrm{MH}$. [Urinary incontinence in women: reasons for not seeking treatment]. Rev Esc Enferm USP. 2009 Mar;43(1):72-8. Portuguese.

9. Visser E, de Bock GH, Kollen BJ, Meijerink M, Berger MY, Dekker JH. Systematic screening for urinary incontinence in older women: who could benefit from it? Scand J Prim Health Care. 2012 Mar;30(1):21-8. 
10. Markland AD, Richter HE, Fwu CW, Eggers P, Kusek JW. Prevalence and trends of urinary incontinence in adults in the United States, 2001 to 2008. J Urol. 2011 Aug:186(2):589-93.

11. Horrocks S, Somerset M, Stoddart H, Peters TJ. What prevents older people from seeking treatment for urinary incontinence? A qualitative exploration of barriers to the use of community continence services. Fam Pract. 2004 Dec;21(6):689-96.

12. Sung W, You H, Yoon TY, Lee SJ. Socioeconomic costs of overactive bladder and stress urinary incontinence in Korea. Int Neurourol J. 2012 Mar;16(1):23-9.

13. Farage MA, Miller KW, Berardesca E, Maibach HI. Psychosocial and societal burden of incontinence in the aged population: a review. Arch Gynecol Obstet. 2008 Apr;277(4):285-90.

14. Hu TW, Wagner TH, Bentkover JD, Leblanc $\mathrm{K}$, Zhou SZ, Hunt T. Costs of urinary incontinence and overactive bladder in the United States: a comparative study. Urology. 2004 Mar;63(3):461-5.

15. Wallner LP, Porten S, Meenan RT, O'Keefe Rosetti MC, Calhoun EA, Sarma AV, et al. Prevalence and severity of undiagnosed urinary incontinence in women. Am J Med. 2009 Nov;122(11):1037-42.

16. Goepel M, Kirschner-Hermanns R, Welz-Barth A, Steinwachs KC, Rübben H. Urinary incontinence in the elderly: part 3 of a series of articles on incontinence. DtschArztebl Int. 2010 Jul;107(30):531-6.

17. Milsom I, Coyne KS, Nicholson S, Kvasz M, Chen $\mathrm{Cl}$, Wein AJ. Global prevalence and economic burden of urgency urinary incontinence: a systematic review. Eur Urol. 2014 Jan;65(1):79-95.

18. Goode PS, Burgio KL, Richter HE, Markland AD. Incontinence in older women. JAMA. 2010 Jun 2:303(21):2172-81.

19. Gerst K, Ray LA, Samper-Ternent R, Espino DV, Markides KS. Self-reported urge urinary incontinence (UUI) among older MexicanAmerican men: risk factors and psycho-social consequences. J Immigr Minor Health. 2011 Dec;13(6):1110-5

20. Barentsen JA, Visser E, Hofstetter $H$, Maris AM, Dekker JH, de Bock GH. Severity, not type, is the main predictor of decreased quality of life in elderly women with urinary incontinence: a population-based study as part of a randomized controlled trial in primary care. Health Qual Life Outcomes. 2012 Dec 18;10:153.

21. Tamanini JT, Lebrão ML, Duarte YA, Santos $\mathrm{JL}$, Laurenti R. Analysis of the prevalence of and factors associated with urinary incontinence among elderly people in the municipality of Sao Paolo, Brazil. Cad Saude Publica. 2009 Aug;25(8):1756-62.

22. Statistical Institute of Jamaica [Internet]. Kingston: Statistical Institute of Jamaica; c2016. Demographic Statistics. Population by Parish. Population and Housing Census 2012 Findings; [cited 2015 Apr 7; updated 2014 Jul 18]. Available from: http://statinja.gov.jm/demo_socialstats/po pulationbyparish.aspx

23. UN International Fund for Agricultural Development [Internet]. New York: United Nations; c2016. Resources. Calculating the Sample Size; [cited 2016 Apr 7]. Available from: https://www .ifad.org/topic/resource/tags/food and nutrition security/2141517

24. Dowling-Castronovo A, Spiro E. Urinary incontinence assessment in older adults: Part II Established Urinary Incontinence. The Hartford Institute for Geriatric Nursing. 2013;11.2.

25. Cameron AP, Heidelbaugh JJ, Jimbo M. Diagnosis and office-based treatment of urinary incontinence in adults. Part one: diagnosis and testing. Ther Adv Urol. 2013 Aug;5(4):181-7.

26. Frank C, Szlanta A. Office management of urinary incontinence among older patients. Can Fam Physician. 2010 Nov;56(11):1115-20.
27. Berger MB, Patel DA, Miller JM, Delancey JO, Fenner DE. Racial differences in self-reported healthcare seeking and treatment for urinary incontinence in community-dwelling women from the EPI Study. Neurourol Urodyn. 2011 Nov;30(8):1442-7.

\section{THE AUTHORS}

Otaniyenuwa Asemota (Corresponding author: asemota@hotmail.com), family physician, Department of Community Health and Psychiatry, Faculty of Medical Sciences, University of the West Indies (FMUWI), Mona, Jamaica.

Denise Eldemire-Shearer, physician with a doctorate in public health, Mona Ageing and Wellness Centre, FMUWI, Mona, Jamaica.

Norman K. Waldron, physician with a master's degree in public health Mona Ageing and Wellness Centre, FMUWI, Mona, Jamaica.

Aileen Standard-Goldson MD, family physician with a master's degree in public health, Department of Community Health and Psychiatry, FMUWI, Mona, Jamaica.

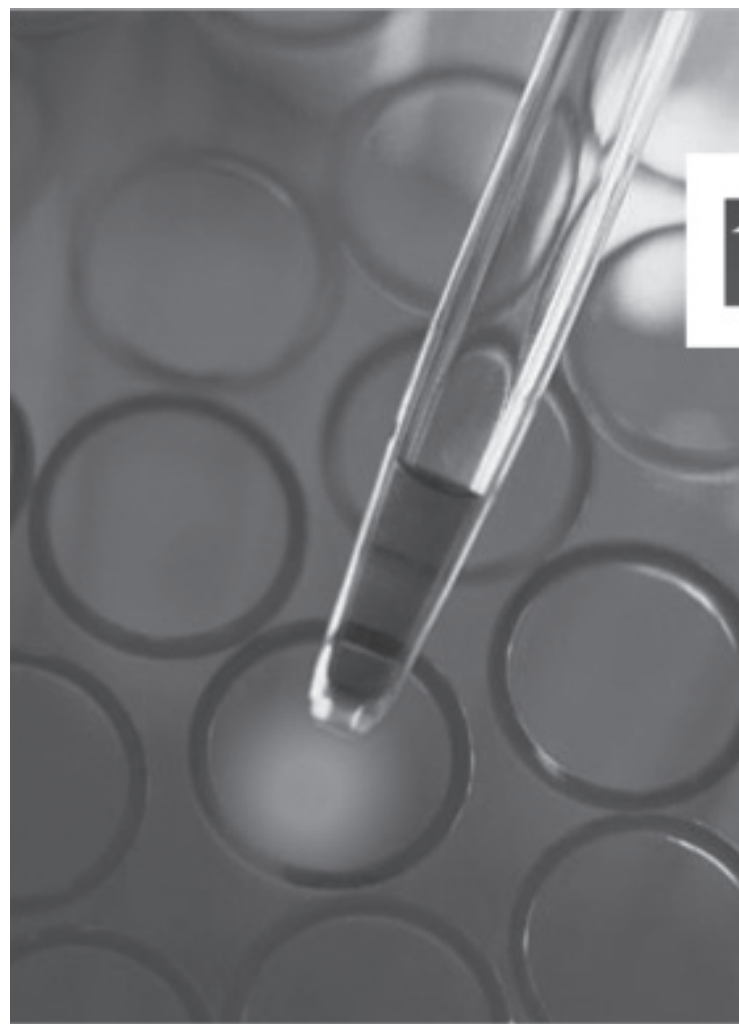

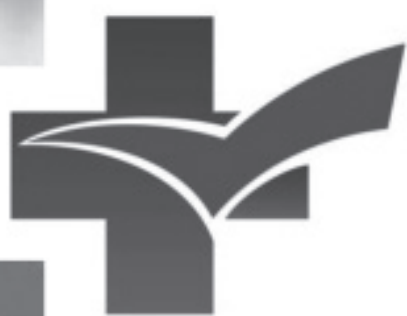

6th International Workshop on Clinical Trials Design and Conduct

November 7-11, 2016

International Convention Center

Havana, Cuba

Main Topics

- Design and conduct of clinical trials

- Guidelines and regulations for clinical trials

- Transparency and ethics in clinical research

- Management of data, statistics and technologies supporting clinical trials

- Clinical trials of natural products

- Training of human resources in clinical research

Chair: Alberto I. Hernández Rodríguez, MD

Contact: http://ensayosclinicos2016.sId.cu 